\section{PROBABILITY AND SCIENTIFIC INFERENCE}

\section{Scientific Inference}

By Sir Harold Jeffreys. Second edition. Pp. viii + 236. (Cambridge : At the University Press, 1957.) 25s. net.

THE first edition of this book was published in

1931. While this second edition has been extensively re-written, the essential principles remain unchanged; as the author puts it in the preface to this new edition: "The general standpoint, that scientific method can be understood if and only if a theory of epistemological probability is provided, remains unaltered". In this theory "prior probabilities' of scientific hypotheses are continually 'being modified by the accumulation of fresh evidence. The consequent unity of outlook, coupled with the author's wide knowledge and exposition of physical theory, is in many ways impressive. Nevertheless, many people, whom Jeffreys would rank as (otherwise) reasonably intelligent, think that in this approach he obscures issues just as much as he considers they do. To quote from one recent publication: ". . . scientists, whose successes we all applaud, do not in fact establish their conclusions by inserting values in their equations for initial prior probabilities. The prior probability story is a rigmarole expounded by probability theorists for one another". ("Foundations of Inductive Logic," by Roy Harrod. London : Macmillan, 1956, p. 149.) Again, Prof. Braithwaite in his book "Scientific Explanation" (Cambridge University Press, 1953) rejects Jeffreys's approach in favour of what, to use a rather clumsy phrase, is termed the 'hypothetico-deductive method'.

One bone of contention has been Jeffreys's apparent reluctance to recognize, as others do, statistical probability as a valid concept in its own right. Naturally such an 'intrinsic probability', as Jeffreys calls it on p. 185, can be discussed in terms of his theory, as the latter is all-embracing, but his adoption of the addition rule (which seems to be introduced rather less clearly, on p. 25, than in the first edition or in his book, "The Theory of Probability", where it is more explicitly noted as a convention) makes this easier to do than it would be otherwise. Statistical properties, which are fundamental in many branches of science, are associated with membership of a group or class, the individuals of which are distinct, but the further distinguishing characteristics of which may be ignored: statistical concepts, like many other scientific concepts, are theoretical concepts used as substitutes for actual phenomena. Just as limiting concepts like position and velocity are allowed, so may statistical probability, which is associated with frequency of occurrence. It is by no means clear that this particular concept is most relevant in the domain of quantum phenomena (consider, for example, the problem of identity), and the attempts to combine quantum theory with the theory of probability are still largely formal (the phase-space distribution quoted on p. 219 is real but not necessarily positive). However, while presumably Jeffreys's probability theory cannot change, statistical theories have the possibility of extension to cope with new conceptual kinds of average.

Sir Harold's own insistence on the importance of probability theory perhaps justifies its possible overemphasis in this review. The author will, from previous experience, scarcely expect all his readers to agree with his views, but he is entitled to expect them to consider these carefully. Whether or not one finally accepts his underlying philosophy, his book as much deserves attention now as when it was first written. It contains, moreover, in a comparatively small space, a fascinating wealth of critical commentary and incidental detail on many topics, such as the foundations of mathematics, sampling, dimensions, mensuration, dynamics and relativity. The emergence in science of convenient concepts like electron or length or temperature or (statistical) probability should not mislead us as to what we observe and what we postulate; and Sir Harold's healthy emphasis on the importance of observational evidence is not one that any scientist, least of all a statistician, would cavil at.

M. S. BARTLETT

\section{THE REFUGEE PROBLEM}

\section{European Refugees}

1939-52. A Study in Forced Population Movement. By M. J. Proudfoot. Pp. 542. (London: Faber and Faber, 1956.) 52s. $6 d$.

THIS book takes up the history of European refugee movements at the point where it was left in Sir John Hope Simpson's study of "The Refugee Problem". It begins with a summary of refugee movements that took place immediately before the War, and then deals with war-time movements - the mass expulsions of populations 'swopped, back and forth by their governments at each major shift in the balance of power, the flight of people before advancing armies and from bombed cities, the desperate attempts to escape starvation and the gas chambers, and the recruitment of workers for the German war machine (recruitment that began as a voluntary influx of free workers and degenerated into slave-raiding expeditions). Next the author describes the plans made by the Allies to cope with the dispersed and homeless they were to encounter in their invasion of Europe, the first tests of these plans in Italy and in France, the mass repatriation of millions in the months following the German collapse, the resettlement of those who refused to be repatriated, and the continuing problems presented by the 'hard core'-many of whom are still living in barracks and public buildings.

The political and administrative history of these movements is traced and documented: the early SHAEF plans, the somewhat unhappy record of UNRRA, the great achievements of the International Refugee Organization, and the continuing work of the United Nations High Commissioner's Office for Refugees-each new organization learning a little from its predecessors, devising fresh expedients to deal with a continually changing situation, and struggling with the apathy of a world that still persists in regarding refugees as a temporary problem.

Mr. Proudfoot's account is laconic, precise and unemotional, even at its dramatic points. See, for example, the story of a group of armed Russian refugees who looted and plundered their way across France until visited by General Dragun, chief Soviet liaison officer in Paris : "He picked out ten Soviet refugees, apparently at random, and shot them himself. After this no more protests were received regarding infractions of discipline by these refugees" (pp. 129-130). 